\title{
Optimum acceptability of recruitment systems: a new multi-criteria approach on human resources
}

María Romero

Luis Romero

\author{
María Luisa Cuadrado and \\ María Isabel de Corcuera
}

\begin{abstract}
Companies today do not have one specific, reliable method for optimally selecting a candidate for a job post. This paper proposes an aggregate acceptability index in order to help companies to establish a 'ranking' of potential candidates in the recruitment processes conducted by the human resources departments. The main advantages of the proposed aggregation index are the following: 1) it takes into account several selection criteria; 2) the procedure for calculating the index is simple; 3 ) the potential candidates can be ranked differently depending on the aggregation structure of the criteria involved. Our theory is applied in a recruitment process based on 15 interviews with potential candidates for a post of responsibility in a finance company. The proposed method is used to hierarchically sort the candidates under consideration according to the company's requirements. This methodology can be applied to the recruitment processes of any company that, based on its requirements, wants to determine the best candidate or candidates for a particular job.
\end{abstract}

Keywords: multiple criteria decision making; MCDM; analytical hierarchy process; recruitment processes; aggregate acceptability index; compromise programming; distance functions; innovation research. 
Reference to this paper should be made as follows: Romero, M., Romero, L., Cuadrado, M.L. and de Corcuera, M.I. (2015) 'Optimum acceptability of recruitment systems: a new multi-criteria approach on human resources', Int. J. Business Innovation and Research, Vol. 9, No. 6, pp.682-697.

Biographical notes: María Romero received her $\mathrm{PhD}$ in Economic and Business Sciences from the Spanish Distance Learning University (UNED) and BA in Business Administration from the Universidad Complutense de Madrid. She has authored several articles and papers related to the field of executive training, other specific aspects of management and business games, as well as multi-criteria decision making. She is Coordinator and Instructor of a MBA in Business Administration degree, and member of the Simulation for Teaching Research Group (GISE) at the UNED.

Luis Romero received his degree and $\mathrm{PhD}$ in Agricultural Engineering from the Technical University of Madrid. Currently, he is teaching mathematics at Spanish Distance Learning University. He has participated in several research projects and authored several articles about renewable energy and decision making.

María Luisa Cuadrado received her $\mathrm{PhD}$ and $\mathrm{BS}$ in Telecommunication Engineering from the Technical University of Madrid. She has participated in numerous research projects from the Spanish National Plan of R\&D and the European Science Foundation, and has authored many scientific papers dealing with applications of finite element methods to different branches of science and technology and with multi-criteria methods applied to finances.

María Isabel de Corcuera received her $\mathrm{PhD}$ in Mathematical Sciences from the Technical University of Madrid and BS in Mathematics from the Universidad Complutense de Madrid. She has participated in numerous research projects from the Spanish National Plan of R\&D and the European Science Foundation, and has authored many scientific papers dealing with applications of finite element methods to different branches of science and technology.

\section{Introduction: personnel selection}

Personnel selection is a process in which a company or organisation selects one or several people among a group of candidates to become part of it. It is a prediction, comparison, and decision process. Prediction because it means predicting who, among the applicants, will be a success in carrying out their functions; comparison, because it endeavours to compare the qualifications of each candidate with the demands of the post; and decision, because it concludes with a selection or classification of the candidates in the order of their suitability or relevance. As can be seen, there are many and heterogeneous elements which have to be analysed and evaluated in each candidate for their subsequent comparison, so that the latter and the selection need to be based on structured techniques logically and scientifically. It is here where the so-called personnel selection models make their appearance, which is the specific point in which this work is framed.

The key selection elements are the clear, precise specification of the requirements of the vacant work post, and the use of multiple techniques for the analysis and assessment of each candidate's conditions and their comparisons. Personnel selection fulfils its aim 
when it places in the company's job positions the ideal candidates to carry out the functions of those posts, with a sufficient capability to be promoted later to positions of a greater responsibility when they have acquired more knowledge and skills.

The importance of personnel selection lies in the fact that it has to optimise, in a multidimensional sense, the potential of the company's human resources. On one hand, the person chosen among the candidates, should be the one most capable of performing the tasks involved in the job. But that is not sufficient in itself. In addition, s/he must be perfectly integrated into the rest of the personnel in order to optimise the overall synergy of the company in the achievement of its short- and long-term objectives. For all this, the candidate selected should feel satisfied with his/her work and identify him/herself with the policies adopted by the company in order for there to be a stable relationship between worker and company. Diverse authors (Roberts, 1997; Breaugh and Starke, 2000) have shown, giving several reasons, that if no adequacy is produced between the requirements and the qualities of the candidate, it is not possible to optimise the company's efficiency.

Also, it should be emphasised that personnel selection is one of the principal modes of building up a company and making it grow. Furthermore, an adequate selection of personnel and its correct training for the challenges of each moment, may determine the company's permanence or disappearance. In relation to the problems raised by globalisation, several authors (Easterby-Smith and Thorpe, 2005) and the Global Competitiveness Report (2010-2011), have precisely indicated the importance of the design of an effective recruitment process for the achievement of entrepreneurial competitiveness in a globalised world.

Finally, with regard to the importance of personnel selection, it can be affirmed that a good selection provides the company with ideal qualifications, which require less training, a shorter adaptation time, higher productivity and efficiency. Also, it helps people to occupy the most suitable post for their personal characteristics, so that these people are more satisfied and stay longer in the company, thus preventing a deterioration in its image due to an increase in personnel rotation.

However, in spite of this importance, a reasonable amount of companies carry out their personnel selection processes using old-fashioned and inefficient methods like observation, the use of subjective data and intuitive or emotive ones, which do not guarantee an acceptable selection of their personnel. Among the arguments, not always true, used in favour of the employment of these methods, are their long duration and the cost of the personnel selection processes, these variables mostly depending on the techniques used in this process. Moreover, the inconveniences caused by the use of these inefficient methods are, among others: high staff rotation, dismissals of unqualified personnel, difficulty of internal promotion, more burdensome procedures for contract termination and, consequently, loss of time and money for companies, as shown by the results obtained by various authors (French, 1991; García et al., 2001; Izard, 2007; Barrett and Meyer, 2010; Li et al., 2013).

\section{Personnel selection models}

During the past few years, the volume of research into personnel selection themes has dramatically increased. However, despite the improvement in the methods used, in most of the techniques the phenomenon of their subjectivity is somewhat imprecise. This means that those techniques applied to the same data by different evaluators arrive at 
different results. Considering the volume of works published, a review has been made briefly analysing the investigations most related to this study, or those which can supply an adequate framework for it.

With regard to the books published on this subject, the following are closest to it: The Blackwell Handbook of Personnel Selection (Evers et al., 2005), and more specifically, Chapter 23 devoted to 'Multilevel selection and prediction theories, methods, models' (Ployhart and Schneider, 2005), which sets out to review the existing personnel selection methods and models, making critiques which will be reiterated by other authors and which we shall comment on later. Another reference taken into account was The Oxford Handbook of Personnel Selection and Assessment (2012), paying special attention to the chapter 'A history of personnel selection and assessment' (Vinchur and Koppes, 2012). Here, too, the main personnel selection methodologies are described and subjectivity again appears to be the fundamental drawback in the methods available. As a complement, we could include the book of Belton and Stewart (2002), which expounds the basic pillars of the multi-criteria method, that of Cascio (2006), which relates productivity to quality and benefit from the perspective of personnel selection, that of Llanos (2008) on interviewing personnel, and that of Montes Alonso and González Rodríguez (2006) on current personnel selection techniques.

As for specific works published, these can be divided into those which deal with selection techniques or complete models, and those which tackle specific issues. Among the former, the construction of a fuzzy model (Petrovic-Lazarevic, 2001) can be included; this is an interesting work although it does not specify the selection of certain fuzzy sets. This work is to a certain extent connected to that of Fengru and Zhang (2011) who have developed a model based on TOPSIS, a software tool which permits a fuzzy treatment of information. The problem of this contribution lies in the logical limitations of the software tool itself. Among similar works which also use TOPSIS or analogical techniques, are that of Dagdeviren (2010), focusing on personnel selection in manufacturing companies, and that of Wang et al. (2006), which permits one to obtain a comparison between the different candidates graphically. In the field of athletism, too, diverse models have been developed (Humara, 2000; Sagas, 2000), although these are naturally very much adapted to this domain and their generalisation in other spheres would be problematic. Another interesting contribution is that of Raju et al. (1991) who setup a two-parameter logistic regression model. This work is of interest but it presents some difficulties in taking into account the many factors employed nowadays in selection processes. With regard to the use of other selection methodologies, there is the PROMETHEE method with linguistic variables (Chen et al., 2009) and ELECTRE, which uses the opinion of experts (Afshari et al., 2010).

In relation to the comparison of selection models, those standing out are the contributions of Wilkins and Sands (1994), who present the comparison of an artificial neuronal networks model with a linear regression one.

The works related to the analysis of specific personnel selection technique elements are highly varied. Those possibly being closest to the aspects contemplated in our work are that of Erekson et al. (2008) who considers the evaluation of management quality as an important element to be borne in mind; that of Moshabaki et al. (2013) who attempt to relate the cognitive and emotional knowledge of employees experimentally with their exploratory and explotative innovations, considering the current importance attributed to innovation processes; the very recent work of De Barros and Dumke (2013) devoted to 
small and medium-sized information technology companies, and that of Kang and Sohal (2011) specialised in high-technology Chinese companies.

Regarding works which look more into the future and whose fundamental merit lies in pointing to directions of interest which ought to be investigated, there is the contribution of Ployhart (2006) relative to selection processes in the 21st century, that of Ryan and Ployhart (2000), who make a critical analysis of the perceptions of candidates and propose to take them into account in future processes, and that of Stevens and Campios (1999) devoted to the selection of work teams.

Finally, it is necessary to mention several reviews of the personnel selection methods carried out at different times, including that of Wiley (1992) and the more recent ones of Gollan (2012) and of Talluri et al. (2013). Reviewers have concluded that we still do not know a great deal about why recruitment activities have the effects that they do, especially considering the subjectivity underlying those personnel selection techniques. In particular, they have criticised many of the studies conducted for being poorly designed, narrow in focus and not grounded in theory.

As a result, a personnel selection model needs to be formulated in the framework of the multiple criteria decision making (MCDM) theory to enable organisations to reconcile, based on their needs at any given time, the number of employees and the qualifications they must have while taking into consideration the anticipated evolution of the staff. The proposed methodology, as we will see, does away with the aforesaid drawbacks that selection processes have presented to date.

The proposed methodology is based on a definition for each candidate of an aggregate acceptability index that accounts for all the selection criteria; the potential candidates are then placed in hierarchical order according to their overall acceptability. This tool permits one to formalise and objectify selection processes, which, as has been remarked, in many cases are subject to the subjectivity of the selection or evaluation committee. This model being a quantitative one it permits the measurement and evaluation of the candidate's profile more exactly, precisely and objectively than other selection methods. Furthermore, in the case of large companies in which internal promotion situations are produced, this tool will also allow a considerable reduction in the possible skews introduced by factors which are alien to the professional profile of the candidate seeking promotion.

It should be noted that, in order for the proposed methodology to be of interest, the aggregate acceptability index should satisfy some common-sense properties, such as:

a Since the number of candidates and criteria in many real-world situations is very large, the index calculation procedure should be a simple one.

b The interpretation of the index should be clear and straightforward.

c The index should represent a good balance between very wide-ranging criteria.

\section{A new personnel selection model}

Let us consider an election set of $\mathrm{n}$ potential candidates in the design of a recruitment process. Each candidate is evaluated according to $\mathrm{m}$ criteria/indicators of acceptability. In a recruitment process, the possible acceptability criteria to be applied to each potential candidate include the following: experience, number of employees supervised, good looks, training received (TR), language knowledge, expected salary (ES), aptitude testing 
(AT), resistance to change, time availability, personal interview (PI), positions of responsibility held, geographical mobility, etc. (Aragón-Sánchez and Esteban-Lloret, 2010).

\subsection{Definition of model inputs}

$\mathrm{P}_{\mathrm{ij}}$ Performance achieved by the $\mathrm{i}^{\text {th }}$ candidate $(\mathrm{i}=1,2, \ldots, \mathrm{n})$ when evaluated according to the $j^{\text {th }}$ criterion $(j=1,2, \ldots, m)$.

$\mathrm{P}^{*}{ }_{\mathrm{j}}$ Optimum value of the $\mathrm{j}^{\text {th }}$ criterion. This value is given by maximum performance if the criterion is of the type 'more is better' (i.e., experience) or by minimum performance if the criterion is of the type 'less is better' (i.e., resistance to change).

$P_{* j}$ Worst value of the $j^{\text {th }}$ criterion. This value is given by minimum performance if the criterion is of the type 'more is better' or by maximum performance if the criterion is of the type 'less is better'.

$\overline{\mathrm{P}}_{\mathrm{ij}}$ normalised performance achieved by the $\mathrm{i}^{\text {th }}$ candidate when evaluated according to the $\mathrm{j}^{\text {th }}$ criterion.

$\mathrm{w}_{\mathrm{j}}$ weight measuring the relative importance attached to the $\mathrm{j}^{\text {th }}$ criterion. By hypothesis it is assumed that $\mathrm{w}_{\mathrm{j}}>0, \mathrm{j}=1,2, \ldots, \mathrm{m}$.

$I_{i}^{A}$ aggregate value index of acceptability for the generic $i^{\text {th }}$ candidate $(i=1,2, \ldots, n)$.

Given that the criteria are mostly measured in different units, the first and absolutely essential step towards constructing the aggregate acceptability index is to normalise the values of $\mathrm{P}_{\mathrm{ij}}$. A simple and pragmatic normalisation procedure successfully used in other contexts (Díaz-Balteiro and Romero, 2004) is as follows:

$$
\bar{P}_{i j}=\frac{P_{i j}-P_{* j}}{P_{j}^{*}-P_{* j}}, \quad i=1,2, \ldots, n, j=1,2, \ldots, m
$$

It is interesting to note that with the normalisation used, the $\overline{\mathrm{P}}_{\mathrm{ij}}$ values are dimensionless, positive and bounded between 0 (when the candidate achieves the worst value) and 1 (when the candidate achieves the best value), respectively.

\subsection{Criteria weight vector}

Among the various possibilities for computing the criteria weight vector $\mathbf{w}=\left(\mathrm{w}_{1}, \mathrm{w}_{2}, \ldots\right.$, $\left.\mathrm{w}_{\mathrm{m}}\right)^{\mathrm{T}} \in \mathfrak{R}^{\mathrm{m}}$, it is proposed to obtain this by applying the dominant eigenvector method $(E V M)$ to the square matrix $A=\left(a_{i j}\right)$ of order $m$, positive $\left(a_{i j} \in \Re / a_{i j}>0\right)$, of diagonal elements one $\left(a_{i i}=1\right)$, reciprocal $\left(a_{i j} \cdot a_{j i}=1\right)$ and generally inconsistent $\left(a_{i j} \neq a_{i k} \cdot a_{k j}\right)$, which is obtained by pair-wise comparison of the $\mathrm{m}$ criteria being considered. This method, developed by Saaty to calculate local priorities in the analytic hierarchy process (AHP) (Saaty, 1980, 1986, 1994, 2003; Saaty and Hu, 1998; Saaty and Vargas, 1984a; Cox, 2012), evaluates the weight vector by resolving the following system of equations:

$$
A \mathbf{w}=\lambda_{\max } \mathbf{w}, \quad \sum_{\mathrm{j}=1}^{\mathrm{m}} \mathbf{w}_{\mathrm{j}}=1
$$


where $\lambda_{\max }$ is the dominant eigenvalue of matrix A.

\subsection{Aggregate acceptability index}

Having ascertained the values of $\bar{P}_{i j} / w_{j}, i=1,2, \ldots, n, j=1,2, \ldots, m$, to establish the aggregate acceptability index $I_{1}^{\mathrm{A}}, \mathrm{i}=1,2, \ldots, \mathbf{n}$ of each of the $\mathrm{n}$ candidates considered, it is necessary to define in $\mathfrak{R}^{\mathrm{m}}$ a distance function between the normalised performance vector achieved by the generic $\mathrm{i}^{\text {th }}$ candidate $\overline{\mathbf{P}}_{\mathrm{ij}}=\left(\overline{\mathrm{P}}_{\mathrm{i} 1}, \overline{\mathrm{P}}_{\mathrm{i} 2}, \ldots, \overline{\mathrm{P}}_{\mathrm{im}}\right)^{\mathrm{T}}$ and the ideal vector $\mathbf{1}=(1,1, \ldots, 1)^{\mathrm{T}}$. With this purpose in mind, the following distance functions are introduced:

$$
\begin{aligned}
\mathrm{L}_{\mathrm{p}}\left(\mathbf{1}, \overline{\mathbf{P}}_{\mathrm{ij}}\right) & =\left[\sum_{j=1}^{\mathrm{m}} \mathrm{w}_{\mathrm{j}}^{\mathrm{p}}\left(1-\overline{\mathrm{P}}_{\mathrm{ij}}\right)^{\mathrm{p}}\right]^{\frac{1}{\mathrm{p}}}, \quad 1 \leq \mathrm{p}<\infty \\
& =\max \left[\mathrm{w}_{\mathrm{j}}\left(1-\overline{\mathrm{P}}_{\mathrm{ij}}\right)\right], \mathrm{p}=\infty
\end{aligned}
$$

From a mathematical point of view, the distances (1) are those induced by the weighted Holder norms defined in the finite dimensional vector space $\mathfrak{R}^{\mathrm{m}}$, regardless of the absolute value to be included in their expressions in order to affect positive magnitudes.

Specifying the $p$ metric in (1), the value of the aggregate acceptability index for the $i^{\text {th }}$ candidate is given by the following expression:

$$
\mathrm{I}_{\mathrm{i}}^{\mathrm{A}}=\mathrm{L}_{\mathrm{p}}\left(\mathbf{1}, \overline{\mathbf{P}}_{\mathrm{ij}}\right)
$$

\subsection{Hierarchical ordering of candidates}

In order to calculate the aggregate acceptability index of the candidates under consideration and to put them into hierarchical order for selection purposes, the following decision rule or behavioural axiom has to be used:

\footnotetext{
"Candidates that are closer to the ideal are preferred over candidates that are farther away from the ideal".
}

The above axiom was introduced in decision theory literature by Zeleny $(1974,1982)$ as the rationale of human choice. It is a convincing rule of behaviour and is suitable for application to our problem.

If we apply the Zeleny axiom to the set of aggregate acceptability indexes $\left\{\mathrm{I}_{\mathrm{i}}^{\mathrm{A}}, \mathrm{i}=1,2, \ldots, \mathbf{n}\right\}$, obtained by applying formula (2) to each of the $\mathbf{n}$ candidates under consideration, we will be able to hierarchically order them for selection purposes. In this way, the first candidate of the hierarchy (i.e., the most acceptable candidate in the specified $p$ metric) will be the one with the lowest value in the calculated aggregate acceptability index (i.e., the candidate that minimises the distance between the vectors $\overline{\mathbf{P}}_{\mathrm{ij}}$ and 1).

It is interesting to note that the solutions (candidates) that obtain the lowest numerical value to the distances (1) for metrics $p=1$ and $p=\infty$ specify the compromise set (Zeleny, 
1974), and it has been verified that the solutions assigning the lowest numerical value to these distances for other values of metric $\mathrm{p}$ generally belong to this set ( $\mathrm{Yu}, 1973$; Blasco et al., 1999). Taking this into account, and in order to calculate in a computationally simple way the aggregate acceptability index $\mathrm{I}_{\mathrm{i}}^{\mathrm{A}}$ for each candidate, given by the generally non-linear formula (2), we propose calculating it for any value of the metric $p$ by evaluating the linear convex combination (Andre and Romero, 2008):

$$
\left.\left.(1-\lambda) \mathrm{L}_{\mathrm{p}}\left(\mathbf{1}, \overline{\mathbf{P}}_{\mathrm{ij}}\right)\right]_{\mathrm{p}=\infty}+\lambda \mathrm{L}_{\mathrm{p}}\left(\mathbf{1}, \overline{\mathbf{P}}_{\mathrm{ij}}\right)\right]_{\mathrm{p}=1}
$$

for values of $\lambda \in[0,1]$.

Specifying the value of $\lambda$ in (3) and considering (1), we obtain:

$$
\mathrm{I}_{\mathrm{i}}^{\mathrm{A}}=(1-\lambda)\left\{\max \left[\mathrm{w}_{\mathrm{j}}\left(1-\overline{\mathrm{P}}_{\mathrm{ij}}\right)\right]\right\}+\lambda \sum_{\mathrm{j}=\mathrm{j}}^{\mathrm{m}} \mathrm{w}_{\mathrm{j}}\left(1-\overline{\mathrm{P}}_{\mathrm{ij}}\right)
$$

The aggregate acceptability indexes given by formula (4) for values $\lambda=1$ and $\lambda=0$ are the same as those given by formula (2) for the metrics $p=1$ and $p=\infty$, respectively. In expression (4), analogously to $\mathrm{p}$ in (2), $\lambda$ is a control parameter that is not only used to obtain different rankings of the candidates, but more importantly, it reflects different structures of the decision-maker's preference with respect to the selection of candidates.

We analyse below the different structures of preference for selecting the best candidate corresponding to the values $\lambda=0$ and $\lambda=1$.

The 'most acceptable candidate' for $\lambda=1$ is the candidate with the best aggregated achievement, i.e., the candidate that maximises the weighted sum of the normalised criteria. This additive solution is the 'best' in aggregate terms but may be unacceptable in practical terms. In fact, a large aggregate average may be compatible with a very poor performance of one of the criteria, which can make the candidate in question ineligible in selection terms.

The 'most acceptable candidate' for $\lambda=0$ is the candidate for which the deviation of the criterion most displaced with respect to the ideal value is minimised. Therefore, the candidate maximising the balance between the achievements of the different criteria being considered is the 'best'.

In many situations, neither of the two previous solutions (candidates) will be acceptable because the 'most acceptable' candidate in one case $(\lambda=1)$ may be a candidate for which the performance of one of the criteria is very poor, and the 'most acceptable' candidate for the other case $(\lambda=0)$ will be very balanced but may have a poor aggregate performance.

One procedure for overcoming these difficulties is to interpret control parameter $\lambda$ as a device for making a trade-off or marginal rates of substitution between average ('efficiency') and balance ('equity'). Thus, compromises or intermediate solutions between the solutions for $\lambda=1$ and $\lambda=0$ can be obtained by assigning values within the open interval $(0,1)$ to parameter $\lambda$. This will output select candidates with sensible properties in terms of both good aggregate performance and good balanced performance.

The following is a case study referring to the design of a recruitment process in a finance company, which will be used to demonstrate the operation and the suitability of the selection procedure described. 


\section{Empirical study}

A comprehensive selection and recruiting policy allows companies to get involved in developing the guidelines for selecting new candidates. Each company needs to understand the current and future requirements of their departments, and to get involved in the recruiting process to help create relevant job descriptions. Managers can also assist in determining experience and educational needs for each new position to make sure that appropriate candidates are recruited.

Most employers want to find the most talented, qualified candidates for their organisations. After all, employees are often the image of the business, and having a great team contributes to overall success. Finding and selecting the best employees for the organisation will entail choosing the proper recruiting media as well as the right screening tools. As mentioned above, although there are many different types of recruitment plans from which to choose, the use of an effective recruitment selection tool is proposed.

In order to describe its usefulness, the methodology suggested in this paper has been applied to a company that is conducting a personnel selection process. The Company has made the decision to look for new Chief Financial Officers (CFOs) because its business plan presents significant growth expectations, raising the possibility of international expansion (basically in the Asia-Pacific region). Since an international presence requires CFOs with a specific profile, the Company has hired a head-hunter in order to receive assistance in the selection process. The head-hunter has been provided with the profile the new CFOs should satisfy: between $35-45$ years old, at least six years' experience in the sector and a very high level of English; additional professional skills will be considered: postgraduate training, knowledge of other languages, international experience, geographic mobility, etc.

Based on the required profile, the head-hunter has identified a selection set of 15 potential candidates that could match it.

Likewise, to determine the importance of the criteria, the company has been consulted as to which requirements are considered to be the most adequate ones in a possible candidate, assigning high, medium or low importance to each professional quality required. This will permit the subsequent setting up of the pair-wise comparison matrix, in which the importance given to each criterion is reflected.

The acceptability criteria (professional skills) and their importance to the company are:

- PI: this is a PI conducted by the Chief Executive Officer (CEO) of the company with the different candidates. The $\mathrm{CEO}$ and the candidate will discuss and analyse the candidate's professional career, as well as the work to be done, reporting process, etc. The CEO will mark each of the candidates on a scale of 1 (does not comply with the required profile) to 5 (complies with all the requirements). This skill is the key one for the company, and that is why this factor is of the highest importance to the company.

- ES: this is the gross annual salary required by the candidate from the head-hunter in order to join the company. Composed of fixed wage, variable pay and entitlement benefits. The variable pay will be calculated according to the gross profit of the 
company and the performance of the candidate during the year. It is measured in thousands of Euros $(\mathrm{k} €$ ). This factor is of great importance to the company.

- English level (EL): all candidates will take the Test of English for International Communication (TOEIC), in order to gauge their EL. The TOEIC was created in 1979 in the USA by the Educational Testing Service (ETS). The full grade goes from 10 to 990 points. It is measured according to the result obtained. This factor is of great importance to the Company.

- Labour experience ( $L E)$ : this is measured in number of years worked. This factor is very important to the Company.

- AT: all the candidates will take a personality test, which is especially designed for personal selection processes. It is a general psychological personality test. It analyses a series of basic dimensions of the personality and professional profile of the candidates. In addition, it helps to evaluate strengths and weaknesses, identifying the professional profile and the competence of the candidate for the job to be filled. The grade goes from 0 (poor competence) to 20 points (high competence). This factor is of medium-low importance to the company.

- TR: includes post-graduate finance and accounting courses taken in the last 3 years. It is measured in hours. The importance of this factor to the company is low.

Using the methodology proposed in this paper, we ranked the 15 candidates according to the values obtained for their aggregate acceptability indexes.

Table 1 shows the performance $P_{i j}, i=1,2, \ldots, 15, j=1,2, \ldots, 6$ achieved by each of the 15 candidates when they were evaluated according to each one of the six acceptability criteria/indicators considered.

Table 1 Values of indicators of acceptability achieved by each candidate

\begin{tabular}{lcccccc}
\hline Candidatos & $\begin{array}{c}\text { Max } \\
\text { personal } \\
\text { interview }\end{array}$ & Min expected salary & $\begin{array}{c}\text { Max } \\
\text { English } \\
\text { level }\end{array}$ & $\begin{array}{c}\text { Max } \\
\text { labour } \\
\text { experience }\end{array}$ & $\begin{array}{c}\text { Min } \\
\text { aptitude } \\
\text { testing }\end{array}$ & $\begin{array}{c}\text { Max } \\
\text { training }\end{array}$ \\
\hline 1 & 4 & $75+(35 * 0,9)=106,5$ & 756 & 10 & 16 & 800 \\
2 & 2 & $60+(30 * 0,9)=87$ & 250 & 7 & 13 & 750 \\
3 & 5 & $65+(35 * 0,9)=96,5$ & 817 & 8 & 7 & 600 \\
4 & 3 & $75+(35 * 0,9)=106,5$ & 600 & 10 & 15 & 800 \\
5 & 1 & $60+(35 * 0,9)=91,5$ & 432 & 6 & 18 & 350 \\
6 & 3 & $80+(50 * 0,9)=125$ & 240 & 14 & 8 & 460 \\
7 & 4 & $60+(60 * 0,9)=114$ & 876 & 6 & 11 & 540 \\
8 & 4 & $70+(50 * 0,9)=115$ & 900 & 8 & 20 & 970 \\
9 & 2 & $75+(45 * 0,9)=120$ & 657 & 13 & 13 & 420 \\
10 & 5 & $70+(40 * 0,9)=106$ & 853 & 9 & 7 & 780 \\
11 & 3 & $70+(45 * 0,9)=110,5$ & 224 & 12 & 15 & 460 \\
12 & 4 & $90+(50 * 0,9)=135$ & 990 & 14 & 8 & 550 \\
\hline
\end{tabular}


Table 1 Values of indicators of acceptability achieved by each candidate (continued)

\begin{tabular}{lcccccc}
\hline Candidatos & $\begin{array}{c}\text { Max } \\
\text { personal } \\
\text { interview }\end{array}$ & Min expected salary & $\begin{array}{c}\text { Max } \\
\text { English } \\
\text { level }\end{array}$ & $\begin{array}{c}\text { Max } \\
\text { labour } \\
\text { experience }\end{array}$ & $\begin{array}{c}\text { Min } \\
\text { aptitude } \\
\text { testing }\end{array}$ & $\begin{array}{c}\text { Max } \\
\text { training }\end{array}$ \\
\hline 13 & 1 & $65+(35 * 0,9)=96,5$ & 780 & 9 & 12 & 1150 \\
14 & 1 & $75+(40 * 0,9)=111$ & 346 & 11 & 17 & 910 \\
15 & 5 & $65+(35 * 0,9)=96,5$ & 876 & 7 & 13 & 540 \\
\hline
\end{tabular}

Table 2 shows the normalised performance $\bar{P}_{i j}, i=1,2, \ldots, 15, j=1,2, \ldots, 6$ achieved by each of the 15 candidates when they were evaluated according to each one of the six acceptability criteria considered. Remember that, in this context, 0 denotes the 'worst' value (anti-ideal), while 1 denotes the 'best' value (ideal).

Table 2 Normalised values of indicators of acceptability achieved by each candidate

\begin{tabular}{lcccccc}
\hline Candidates & $\begin{array}{c}\text { Personal } \\
\text { interview }\end{array}$ & $\begin{array}{c}\text { Expected } \\
\text { salary }\end{array}$ & $\begin{array}{c}\text { English } \\
\text { level }\end{array}$ & $\begin{array}{c}\text { Labour } \\
\text { experience }\end{array}$ & $\begin{array}{c}\text { Aptitude } \\
\text { testing }\end{array}$ & Training \\
\hline 1 & 0,7500 & 0,5938 & 0,6945 & 0,5000 & 0,6923 & 0,5625 \\
2 & 0,2500 & 1 & 0,0339 & 0,1250 & 0,4615 & 0,5000 \\
3 & 1 & 0,8021 & 0,7742 & 0,2500 & 0 & 0,3125 \\
4 & 0,5000 & 0,5938 & 0,4909 & 0,5000 & 0,6154 & 0,5625 \\
5 & 0 & 0,9063 & 0,2715 & 0 & 0,8462 & 0 \\
6 & 0,5000 & 0,2083 & 0,0209 & 1 & 0,0769 & 0,1375 \\
7 & 0,7500 & 0,4375 & 0,8512 & 0,0000 & 0,3077 & 0,2375 \\
8 & 0,7500 & 0,4167 & 0,8825 & 0,2500 & 1 & 0,7750 \\
9 & 0,2500 & 0,3125 & 0,5653 & 0,8750 & 0,4615 & 0,0875 \\
10 & 1 & 0,6042 & 0,8211 & 0,3750 & 0 & 0,5375 \\
11 & 0,5000 & 0,5104 & 0 & 0,7500 & 0,6154 & 0,1375 \\
12 & 0,7500 & 0 & 1 & 1 & 0,0769 & 0,2500 \\
13 & 0 & 0,8021 & 0,7258 & 0,3750 & 0,3846 & 1 \\
14 & 0 & 0,5000 & 0,1593 & 0,6250 & 0,7692 & 0,7000 \\
15 & 1 & 0,8021 & 0,8512 & 0,1250 & 0,4615 & 0,2375 \\
\hline & & & & & & 2 \\
\hline
\end{tabular}

Also, taking into account the considerations made on the acceptability criteria, in accordance with the professional qualities required from the candidates by this company, and making use of the Saaty (1980) scale, the pair-wise comparison matrix of the six criteria considered is the following [A: $\left(\mathrm{a}_{\mathrm{ij}}\right)$ of the order $\left.\left.\mathrm{m}=6\right)\right]$ : 
Figure 1 Pair-wise comparison matrix A: $\left(a_{i j}\right)$ of the order $m=6$ )

\begin{tabular}{|c|c|c|c|c|c|c|}
\hline & PI & ES & EL & LE & $\mathrm{AT}$ & $\mathrm{TR}$ \\
\hline PI & $(1$ & 3 & 2 & 4 & 6 & 7 \\
\hline ES & $\frac{1}{3}$ & 1 & 3 & 2 & 5 & 6 \\
\hline EL & $\frac{1}{2}$ & $\frac{1}{3}$ & 1 & 2 & 4 & 5 \\
\hline LE & $\frac{1}{4}$ & $\frac{1}{2}$ & $\frac{1}{2}$ & 1 & 2 & 3 \\
\hline $\mathrm{AT}$ & $\frac{1}{6}$ & $\frac{1}{5}$ & $\underline{1}$ & 1 & 1 & 2 \\
\hline TR & $\frac{1}{7}$ & $\frac{1}{6}$ & $\frac{1}{5}$ & $\frac{1}{3}$ & $\frac{1}{2}$ & 1 \\
\hline
\end{tabular}

Source: Own elaboration

Figure 2 Ordering of candidates for $\lambda=0.625$

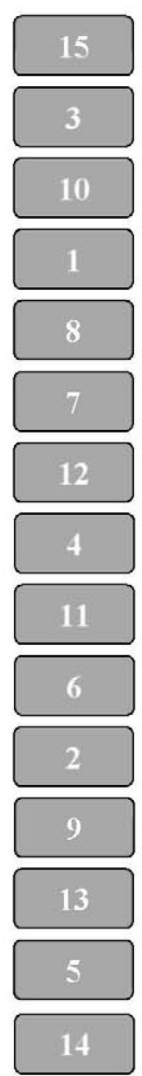




\section{Source: Own elaboration}

Applying to this matrix the EVM method, we obtained the following criteria weight vector:

$$
\mathbf{w}:(0.393,0.251,0.167,0.100,0.053,0.036)^{\mathrm{T}} \in \mathfrak{R}^{6}
$$

With these data and applying the Zeleny axiom to the set of values $\left\{I_{i}^{A}, i=1,2, \ldots, 15\right\}$ obtained by solving formula (4) for 'different values of $\lambda$ ', we obtain 'different rankings' of the 15 candidates that show 'different structures of selection preferences'. This will allow the company to easily select the most suitable candidates at any given time of its expansion procedure according to its changing needs. For the selection of $\lambda$, this starts off from the need to select a value belonging to the interval $(0.1)$ for this parameter. Therefore, $\lambda$ is calculated by initially situating the parameter in an intermediate position (initial mean value). Subsequently, the company itself, given its conjunctural situation and its current expectations, will decide to evaluate in a higher or lower percentage, which specific characteristics it is seeking in its candidates.

This company called together its management team, and, after carrying out a brainstorming, it decided to make the selection in valuing at a higher percentage certain characteristics aggregated in the candidates; to be specific it applied a $25 \%$ deviation over the average. Thus, the company has granted greater importance to the 'optimum average achievement' than the 'optimum balance achievement' assigning to $\lambda$ the following value:

$$
\lambda=0.5+25 \%(0.5)=0.625 € €
$$

With the aim of detecting the possible margin of error committed by the company in its assessments, a sensitivity analysis was performed between the range $0.600-0.650$. This allowed the company to verify if the results obtained in its brainstorming were accurate since the first three candidates selected remained in an unalterable order in that sensitivity analysis.

Figure 2 shows the ordering of candidates for $\lambda=0.625$. Candidate number 15 will be the one selected as CFO.

\section{Conclusions and further research}

The basic task when selecting personnel is to choose from among the recruited candidates the ones that will most likely adapt to the offered job post and do the job well.

The proposed methodology, based on the use of parameter $\lambda$, enables the establishment of different hierarchical rankings of candidates. Bearing in mind the current economic situation in which turnover is very high and the pool of potential candidates very large, what would be considered as ideal is the middle ground between the extreme rankings corresponding to $\lambda=0$ (most balanced achievement) and $\lambda=1$ (best aggregate achievement). The comparative analysis of these possibilities in relation to the company's criteria and needs will make it possible to determine at any given time the most appropriate value of $\lambda$ to obtain the most suitable candidate ranking.

At present, the main drawback in the recruitment processes of most companies is the non-uniformity of these processes. This leads to an indiscriminate use of methods, 
techniques, instruments, time and equipment and unnecessarily increases costs in organisations. The aggregate acceptability index proposed in this paper can circumvent these difficulties, and it can be used to hierarchically to sort any number of possible candidates.

In fact, the computation of the aggregate index is very simple and the 'additive' case is just one of the different options for aggregating the considered criteria. Bearing this in mind, the generation of a 'ranking' of candidates, according to an aggregate acceptability index aims to reduce the impact of the problem of subjectivity with which corporate human resource departments often have to deal.

This methodology could put an end to the disadvantages currently presented by selection processes and allow for a greater personnel stability and permanence, a reduction in staff rotation and investments and efforts in qualification, the gradual improvement of human potential by systematic selection of the best talents, and, consequently, enhanced corporate productivity and performance.

The aggregate acceptability index will allow companies to standardise, formalise and objectify their recruitment processes and select the most suitable candidate according to the required profile.

Possible extensions of this research are:

- To implement a sensitivity analysis of the value judgements made on building the pair-wise comparison matrix of the criteria to validate the robustness of the obtained candidate selection hierarchy.

- To treat the preferential weights as unknowns in order to elicit the weight vector that can provide a better hierarchical ranking of candidates at any given time in the company.

\section{Acknowledgements}

We would like to acknowledge the valuable input and insightful comments made by the two anonymous reviewers of this paper. Thanks are also tendered to all the candidates who participated in this study.

\section{References}

Afshari, A.R., Mojahed, M., Yusuff, R.M., Hong, T.S. and Ismail, M.Y. (2010) 'Personnel selection using ELECTRE', Journal of Applied Sciences, Vol. 10, No. 23, pp.3068-3075.

Andre, F.J. and Romero, C. (2008) 'Computing compromise solutions: on the connections between compromise programming and composite programming', Applied Mathematics and Computation, Vol. 195, No. 1, pp.1-10.

Aragón-Sánchez, A. and Esteban-Lloret, N. (2010) 'La formación en la empresa española: ¿sólo se busca mejorar los resultados organizacionales?', Universia Business Review, Vol. 49, No. 26, pp.35-49.

Barrett, R. and Meyer, M. (2010) 'Correlates of perceiving human resource management as a 'problem' in smaller firms', Asia Pacific Journal of Human Resources, Vol. 48, No. 2 , pp.133-150.

Belton, V. and Stewart, T.J. (2002) Multiple Criteria Decision Analysis. An Integrated Approach, Kluwer Academic Publishers, Boston. 
Blasco, F., Cuchillo-Ibáñez, E., Alonso-Morón, M. and Romero, C. (1999) ‘On the monotonicity of the compromise set in multicriteria problems', Journal of Optimization Theory and Applications, Vol. 102, No. 1, pp.69-82.

Breaugh, J.A. and Starke, M. (2000) 'Research on employee recruitment: so many studies, so many remaining questions', Journal of Management, Vol. 26, No. 3, pp.405-434.

Cascio, W. (2006) Managing Human Resources. Productivity, Quality of Work Life, Profits, McGraw Hill Irwin, New York.

Chen, C., Hwang, Y. and Hung, W. (2009) 'Applying multiple linguistic PROMETHEE method for personnel evaluation and selection', Industrial Engineering and Engineering Management, IEEM International Conference.

Cox, M.A. (2012) 'Which is the appropriate triangular distribution to employ in the modified analytic hierarchy process?', Journal of Management Mathematics, Vol. 23, No. 3, pp.227-239.

Dagdeviren, M. (2010) 'A hybrid multi-criteria decision-making model for personnel selection in manufacturing systems', Journal of Intelligent Manufacturing, Vol. 21, No. 4, pp.541-460.

De Barros, T. and Dumke, D. (2013) 'Enabling the strategic planning of small and medium-sized information technology through advanced results: a configurational perspective of Mintberg 5Ps', International Journal of Business Innovation and Research, Vol. 7, No. 6, pp.663-678.

Díaz-Balteiro, L. and Romero, C. (2004) 'In search of a natural systems sustainability index', Ecological Economics, Vol. 49, No. 3, pp.399-403.

Easterby-Smith, M. and Thorpe, R. (2005) 'Research traditions in management learning', in Burgoyne, J. and Roynolds, M. (Eds.): Management Learning: Integrating Theory and Practice, Sage, London.

Erekson, O., Gorman, R. and Molloy, L. (2008) 'Innovation in environmental performance: the importance of financial performance and management quality', International Journal of Business and Innovation Research, Vol. 2, No. 4, pp.331-353.

Fengru, X. and Zhang, L. (2011) 'A personnel selection model based on TOPSIS', Management Science and Engineering, Vol. 5, No. 3, pp.107-110.

French, S. (1991) 'Recent mathematical developments in decision analysis', Journal of Management Mathematics, Vol. 3, No. 1, pp.1-12.

García Noya, M., Hierro Díez, E. and Jiménez Bozal, J.J. (2001) Selección de personal: sistema integrado, ESIC, Madrid.

Global Competitiveness Report (2010-2011) [online] htttp://www3.weforum.org/docs/WEF GlobalCompetitivenessReport 2010-11.pdf (accessed $11 / 10 / 2012)$.

Gollan, P.J. (2012) 'HR on the line: human resource managers' contribution to organisational value and workplace performance', Asia Pacific Journal of Human Resources, Vol. 50, No. 3, pp.288-307.

Humara, M. (2000) 'Personal selection in athletic programs', Online Journal of Sport Psychology, Vol. 2, No. 2, pp.1-7.

Izard, M.O. (2007) 'El proceso de captación y selección de personal', GESTIÓN 2000, Argentina.

Kang, J. and Sohal, A. (2011) 'Human resource management in Chinese hi-tech enterprises: a case study', International Journal of Business Innovation and Research, Vol. 5, No. 2, pp.179-191.

Li, A., Bagger, J. and Friske, W. (2013) 'Social desirability in the selection process: new insights from a novel context', Asia Pacific Journal of Human Resources, Vol. 51, No. 1, pp.45-62.

Llanos, J.R. (2008) Como entrevistar en la selección de personal, Pax, México.

Montes Alonso, M.J. and González Rodríguez, P. (2006) Selección de personal: la búsqueda del candidato adecuado, Ideaspropias, S.L. Vigo.

Moshabaki, A., Dabestani, R. and Saljoughian, M. (2013) 'Clustering employees on the basis of their cognitive and emotional knowledge and analysing their exploratory and exploitative innovations: a case study in a service company', International Journal of Business Innovation and Research, Vol. 7, No. 6, pp.679-698. 
Petrovic-Lazarevic, S. (2001) 'Personnel selection fuzzy model', International Transactions in Operational Research, Vol. 8, No. 1, pp.89-105.

Ployhart, R.E. (2006) 'Staffing in the 21 st century: new challenges and strategic opportunities', Journal of Management, Vol. 32, No. 6, pp.868-897.

Ployhart, R.E. and Schneider, B. (2005) 'Multinevel selection and prediction: theories methods models (Chapter 23)', in Evers, A., Anderson, N. and Smit-Voskuijl, O. (Eds.): The Blackwell Handbook of Personnel Selection, Blackwell Publishing.

Raju, N., Steinhaus, S., Edwards, J. and DeLessio, J. (1991) 'A logistic regression model for personnel selection', Applied Psychological Measurement, Vol. 15, No. 2, pp.139-152.

Roberts, G. (1997) Recruitment and Selection: A Competency Approach, The Cromwell Press, Wiltshire, Great Britain.

Ryan, A.M. and Ployhart, R.E. (2000) 'Applicants' perceptions of selection procedures and decisions: a critical review and agenda for the future', Journal of Management, Vol. 26, No. 3 , pp.565-606.

Saaty, T.L. (1980) The Analytic Hierarchy Process, McGraw-Hill, New York.

Saaty, T.L. (1986) 'Axiomatic foundation of the analytic hierarchy process', Management Science, Vol. 32, No. 7, pp.841-855.

Saaty, T.L. (1994) 'Highlights and critical points in the theory and application of the analytic hierarchy process', European Journal of Operational Research, Vol. 74, No. 3, pp.426-447.

Saaty, T.L. (2003) 'Decision-making with the AHP: why is the principal eigenvector necessary?', European Journal of Operation Research, Vol. 145, No. 1, pp.85-91.

Saaty, T.L. and Hu, G. (1998) 'Ranking by eigenvector versus other methods in the analytic hierarchy process', Applied Mathematics Letters, Vol. 11, No. 4, pp.121-125.

Saaty, T.L. and Vargas, L. (1984a) 'Comparison of eigenvalue, logarithmic least squares and least squares methods in estimating ratios', Mathematical Modeling, Vol. 5, No. 5, pp.309-324.

Saaty, T.L. and Vargas, L. (1984b) 'Inconsistency and rank preservation', Journal of Mathematical Psychology, Vol. 28, No. 2, pp.205-214.

Sagas, M. (2000) 'Utilizing the person-organization fit model of personnel selection in athletic programs', Athletic Insight, Vol. 2, No. 3, pp.229-250.

Stevens, M.J. and Campios, M.A. (1999) 'Staffing work teams: development and validation of a selection test for teamwork settings', Journal of Management, Vol. 25, No. 2, pp.207-228.

Talluri, S., DeCampos, H.A. and Hult, G. (2013) 'Supplier rationalization: a sourcing decision model', Journal of the Decision Sciences, Vol. 44, No. 1, pp.57-86.

Vinchur, A.J. and Koppes, L. (2012) 'A history of personnel selection and assessment', in The Oxford Handbook of Personnel Assessment and Selection, Oxford Handbooks Online Publishing, Oxford University Press.

Wang, T.C., Liou, M.C. and Hung, H.H. (2006) 'Selection by TOPSIS for surveyor of candidates in organizations', International Journal of Services Operations and Informatics, Vol. 1, No. 4, pp.332-346.

Wiley, C. (1992) 'Recruitment research revisited: effective recruiting methods according to employment outcomes', Journal of Applied Business Research, Vol. 8, No. 2, pp.74-79.

Wilkins, C.A. and Sands, W.A. (1994) 'Comparison of a back propagation artificial neural network model with a linear regression model for personnel selection', Navy Personnel Research and Development Center, NPRDC-TN-94-18.

Yu, P.L. (1973) 'A class of solutions for group decision problems', Management Science, Vol. 19, No. 8, pp.936-946.

Zeleny, M. (1974) 'A concept of compromise solutions and the method of the displaced ideal', Computers and Operations Research, Vol. 1, No. 4, pp.479-496.

Zeleny, M. (1982) Multiple Criteria Decision Making, McGraw-Hill, New York. 